\title{
Article
}

\section{Preparing midwifery students for traumatic workplace events: Findings from the POPPY (programme for the prevention of posttraumatic stress disorder in midwifery) feasibility study}

Spiby, Helen, Sheen, Kayleigh, Collinge, Sarah, Maxwell, Clare, Pollard, Kerry and Slade, Pauline

Available at http://clok.uclan.ac.uk/24640/

Spiby, Helen, Sheen, Kayleigh, Collinge, Sarah, Maxwell, Clare, Pollard, Kerry and Slade, Pauline (2018) Preparing midwifery students for traumatic workplace events: Findings from the POPPY (programme for the prevention of posttraumatic stress disorder in midwifery) feasibility study. Nurse Education Today, 71 . pp. 226-232. ISSN 0260-6917

It is advisable to refer to the publisher's version if you intend to cite from the work. http://dx.doi.org/10.1016/j.nedt.2018.09.024

For more information about UCLan's research in this area go to http://www.uclan.ac.uk/researchgroups/ and search for <name of research Group>.

For information about Research generally at UCLan please go to http://www.uclan.ac.uk/research/

All outputs in CLoK are protected by Intellectual Property Rights law, including Copyright law. Copyright, IPR and Moral Rights for the works on this site are retained by the individual authors and/or other copyright owners. Terms and conditions for use of this material are defined in the policies page. 
Title: PREPARING MIDWIFERY STUDENTS FOR TRAUMATIC WORKPLACE EVENTS: FINDINGS FROM THE POPPY (PROGRAMME FOR THE PREVENTION OF POSTTRAUMATIC STRESS DISORDER IN MIDWIFERY) FEASIBILITY STUDY

Authors: Professor Helen Spiby ${ }^{1}$; Professor of Midwifery, University of Nottingham; Dr Kayleigh Sheen²; Lecturer in Psychology, Liverpool John Moores University; ${ }^{3}$ Dr Sarah Collinge ${ }^{3}$; Clinical Psychologist, East Lancashire NHS Foundation Trust; Clare Maxwell, Senior Lecturer/ Postgraduate Researcher, Liverpool John Moores University; Kerry Pollard, Midwifery Lecturer, University of Central Lancashire5; Professor Pauline Slade ${ }^{2 *}$; Professor of Clinical Psychology \& Consultant Clinical Psychologist; University of Liverpool

${ }^{1} 12^{\text {th }}$ Floor, Tower Building, University Park, Nottingham, NG7 2RD, UK. Email: helen.spiby@nottingham.ac.uk Tel: 01158230820

${ }^{2}$ School of Natural Sciences and Psychology, Tom Reilly Building, Byrom Street, L3 3AF. Email: k.s.sheen@limu.ac.uk

${ }^{3}$ East Lancashire Hospitals NHS Trust, Royal Blackburn Hospital, Haslingden Road, Blackburn, BB2 3HH. Email: sarah.e.collinge@googlemail.com

${ }^{4}$ School of Nursing and Allied Health, 79 Tithebarn Street, Liverpool, L2 2ER. Tel: 01512314556. Email: c.maxwell@ljmu.ac.uk

${ }^{5}$ College of Health and Wellbeing, School of Community Health and Midwifery. Brook BuildingRoom 221,Preston, PR1 2HE.tel: 01772 895486.Email: kapollard1@uclan.ac.uk

${ }^{6}$ Institute of Psychology, Health \& Society, Ground Floor Whelan Building, University of Liverpool, Brownlow Hill, Liverpool, L69 3GB. Email: Pauline.slade@liverpool.ac.uk Tel: 01517945485

Funding: This work was supported by Health Education England (Working Across The North)

Acknowledgements: The authors would like to thank the students and midwifery educators at Liverpool John Moores University and the University of Central Lancashire for their time, facilitation, and input

Conflict of interest: None.

Correspondence: Please address correspondence to Professor Pauline Slade, Institute of Psychology, Health \& Society, Ground Floor Whelan Building, University of Liverpool, Brownlow Hill, Liverpool, L69 3GB. Email: Pauline.slade@liverpool.ac.uk Tel: 01517945485 
ABSTRACT (296/300)

Background: Midwifery students can experience events on clinical placements that they perceive to be traumatic. There is currently no requirement to provide training about the nature of trauma, normal responses, or the most helpful ways of self-managing these. The POPPY programme, developed for qualified midwives, incorporates educational (the POPPY workshop) and supportive resources to prevent the development of Post-Traumatic Stress Disorder in midwives. As part of the feasibility evaluation of POPPY, the POPPY workshop element was adapted for pre-registration midwifery students (PreR-POPPY). Attention to this issue during pre-registration education could improve student experience and support student retention. Objectives: To identify students' perspectives on the contents (clarity, understandability, organisation of the workshop, utility, relevance), their understanding of trauma and psychological responses, and confidence in recognising and managing early signs of distress following participation in a PreR-POPPY workshop. Perspectives on preferred timing in their midwifery programmes, and methods of delivery were also sought. Design: In keeping with educational evaluations, anonymous feedback was collected from students. Setting: Two higher education institutes. Participants: Midwifery undergraduate students on the three year or shortened programme for registered nurses $(n=131)$, and midwifery educators $(n=5)$. Methods: Students participated in the workshop and provided feedback immediately. Midwifery educators participated in a meeting with the researchers to provide feedback. Results: High levels of satisfaction with the contents of the workshop were identified. Ninety-nine percent of students would recommend the workshop to other midwifery students. Provision of the workshop early in midwifery programmes, revisited at later points, was strongly endorsed. Learning outcomes were very positive for understanding trauma/ early stress responses, and recognising and managing early responses to trauma. Strong endorsement for the provision of the workshop was received from the midwifery educators. Conclusions: The pre-registration adapted POPPY workshop should be routinely provided in preregistration midwifery.

KEYWORDS: Student midwives, pre-registration midwives, trauma, Post Traumatic Stress Disorder 
WHOLE TEXT Inc. abstract and references (5009/5000)

\section{INTRODUCTION}

There is increasing recognition of midwives potentially experiencing traumatic events whilst providing care, and for a significant proportion to be at risk of developing symptomatic responses commensurate with posttraumatic stress disorder (PTSD) (Cohen et al., 2017; Leinweber, Creedy, Rowe \& Gamble, 2017; Sheen, Spiby \& Slade, 2015; Wahlberg et al., 2016). PTSD involves distressing and involuntary recollection of a traumatic event (e.g., via flashbacks, nightmares, intrusive thoughts), avoidance of reminders (people, places, thoughts), hyperarousal (feeling 'on edge', irritable, difficulty sleeping or concentrating) and negative changes to mood and beliefs (e.g., guilt, shame or self-blame) (APA, 2013). PTSD is acutely distressing and if not appropriately managed may be enduring (NICE, 2005).

A national survey of UK midwives indicated that at least one in 20 qualified midwives may experience clinically relevant symptoms of posttraumatic stress disorder following a traumatic experience encountered at work (Sheen et al., 2015). Experiencing a traumatic event in this context holds implications for midwives' own personal and professional wellbeing, with midwives reporting changing their clinical allocation, taking time away from practice, or considering leaving the midwifery profession altogether (Leinweber et al., 2017b, Sheen et al., 2015; Wahlberg et al., 2016). The experience of trauma has also been associated with a tendency for midwives to practice more defensively, or to depersonalise recipients of their care (Elmir et al., 2017), with implications for women's experiences throughout the perinatal period.

There is an emerging body of literature investigating student midwives' experiences of difficult or traumatic events (Barry et al., 2017; Davies \& Coldridge, 2015; Coldridge \& Davies, 2017). Davies and Coldridge (2015) interviewed $1^{\text {st }}$ and $3^{\text {rd }}$ year undergraduate students $(n=11)$ to explore the nature of their traumatic experiences, and their perceptions on available support. Students reported feeling overwhelmed with the responsibility of certain situations, feeling unprepared for how a seemingly 'normal' birth can become complicated, and questioning their own ability to manage the emotional demands of the role (Davies \& Coldridge, 2015). Students also reported feeling 'left to their own devices' to find ways of coping with their emotional responses to events encountered at work. In a secondary phenomenological analysis of the interviews, students perceived there was only limited recognition by colleagues of their need to discuss events that had made them anxious and an absence of emotional support (Coldridge \& Davies, 2017).

There is increasing international recognition of the need to develop systematic ways to prepare and support both the current and future midwifery workforce in relation to potential trauma experience (Leinweber et al., 2017; Cohen et al., 2017; Power \& Mullen, 2017)). This would benefit midwives, 
women in receipt of care, and maternity organisations. Attention to this issue during pre-registration education has the potential to improve the experience of students and reduce training attrition. This issue is particularly pertinent as recent figures indicate a $5 \%$ reduction in the number of student midwives, despite university places remaining the same (RCM, 2017). The current shortage of qualified midwives further emphasises the requirement to support retention throughout training programmes for the benefit of the future midwifery workforce (RCM, 2017).

The POPPY programme (programme for the prevention of PTSD in midwifery) is an educational and supportive package of resources aimed at preventing the development of PTSD in response to workplace trauma in midwifery staff. It was developed from psychological theory integrated with primary research from qualified midwives (Sheen et al., 2015, 2016a, 2016b). A key component of the POPPY programme is universal prevention in the form of a training workshop a training workshop (the POPPY workshop) providing information on the development of PTSD and guidance on self-help strategies, supported by an information leaflet. Additional resources in the full POPPY package include targeted prevention in the form of a confidential peer support system, and access to trauma-focussed psychological intervention where required. The POPPY programme was developed and recently implemented in one NHS Trust as part of the feasibility and acceptability evaluation of the resources for qualified midwives (Slade, Sheen, Collinge, Butters, Spiby, in submission).

The POPPY workshop is a two-hour psychoeducational session providing information about the nature of traumatic experiences and psychological responses. The workshop is divided into three sections; section (1) provides an introduction to the topic, including reference to previous research that directly informed the focus of the POPPY workshop, section (2) provides information on the nature of trauma responses, normal early psychological processes, and the development of PTSD, and section (3) introduces strategies that can be used to self-manage early responses to trauma to aid processing. Information on when and where to seek appropriate support is also provided in section 3. The workshop includes discussion-based activities to elaborate and promote engagement with learning content.

Although the POPPY workshop was grounded in the experiences of qualified midwives, an additional component of the feasibility evaluation of the POPPY programme involved adaptation of the training material for provision for pre-registration midwifery students.

\section{Preregistration adaptation process}

The adaptation of the PreR-POPPY workshop involved careful consideration to align material with current methods for preparing and supporting undergraduate development. A multidisciplinary team, 
with expertise in clinical psychology, health psychology and midwifery, developed the original POPPY workshop and the pre-registration adaptation (PreR-POPPY). Student specific examples were integrated into the existing scenarios, and material and contextual details throughout the workshop adapted to include reference to pre-registration midwifery students. Discussion-based activities were also altered to focus on the perspectives of the student midwife, and guidance on accessing further support within the host HEl context included.

\section{Objectives}

To gather feedback from pre-registration midwifery students regarding the acceptability and perceived utility of the adapted POPPY workshop with regards to contents, resources and preferred timing and method of delivery.

\section{METHOD}

\section{Procedure}

Permission was received from two Higher Education Institutes (HEl's) in the North-West of England for members of the POPPY research team to provide the PreR-POPPY workshop to students registered on their pre-registration midwifery programmes. One HEI provided both 3 year and shortened (20 month) programmes, and one HEI provided the 3 year programme. Between April and July 2017 seven workshops were provided for students registered on each year of the midwifery programmes at each $\mathrm{HEl}$. Prior to each workshop, information about the session was distributed to a representative from each $\mathrm{HEI}$ for wider dissemination. This provided a brief overview of the aims and scope of the workshop, with citations for further relevant reading. A midwifery educator from the host HEI was present at each workshop.

\section{Participants}

137 pre-registration midwifery students attended the PreR-POPPY training; 41 in their first year of a three-year course, 42 in their second year, 40 in their final year and 14 students in their first year of the shortened (20-month) programme.

\section{Collection of anonymous feedback from midwifery students}

In keeping with educational evaluations, anonymous feedback was collected in hard copy from students following each workshop to identify perspectives on:

1. Workshop contents (clarity, understandability, organisation of the workshop including perceived utility and relevance), scored 0 (not at all) to 10 (extremely) with higher scores indicating more positive endorsement

2. Personal understanding and skills (clarity of understanding about trauma experiences, trauma responses and confidence in recognising early signs of distress, managing early 
stress responses using self-help strategies), scored 0 (not at all) to 10 (extremely) with higher scores indicating positive endorsement

3. Possible timing in the midwifery programme (never, year 1, year 2, year 3, a combination, other) including a free text response to elaborate on the response

4. Preferred method of delivery (standalone, series in different modules, series in one module, in another way) including a free text response to elaborate on the response

5. Additional considerations, improvements (free text response)

Feedback forms were reviewed and approved by midwifery educators in the host institutions prior to use.

\section{Collection of feedback from midwifery educators}

A meeting was convened with midwifery educators $(n=5)$ from each host site, all of whom had been present during a PreR-POPPY workshop. The purpose of the meeting was to collect feedback from a midwifery educator perspective with regards to the utility and relevance of the workshop, optimal timing and placement within midwifery training programmes, and to consider methods of integration into the existing midwifery curriculum.

\section{Analysis}

Students were grouped by year of study (years 1-3 of the 3 year programme, shortened programme). Descriptive statistics were computed using SPSS 22 to calculate mean scores for scales assessing the content of the PreR-POPPY workshop and learning outcomes, and proportions endorsing each option for the timing and method of delivery. The proportion of students scoring 9 or above (out of 10) for each domain was calculated to explore inter-group differences. Inferential analyses (on- way analysis of variance [ANOVA] tests) were conducted to check for any differences across year groups. A power analysis indicated that a total sample size of 111 was sufficient (power $80 \%$, alpha $=.05$, effect size $=.3$ ). Where the assumption for homogeneity of variance was violated (indicated by Levene's Test of Homogeneity of Variance), Brown-Forsythe was used as an alternative F-ratio, and Games-Howell used to infer post-hoc analyses. Free text responses were analysed using thematic analysis (Braun \& Clark, 2006) to identify commonalities in students' perspectives.

\section{$\underline{\text { RESULTS }}$}

The contents of the PreR-POPPY workshop 
This was evaluated via six domains assessing clarity, understandability, organisation, level of interest, perceived utility and relevance. Overall mean scores were very high, indicating positive perceptions on all dimensions. Means and medians are presented in (Table 1).

Scores were also grouped by year group (year 1, year 2, year 3 and first year on the 18 month course) to examine whether perceptions about the workshop contents differed by year group. Findings indicated that there was a tendency for students registered in their first and third year to report higher scores across all domains (Table 1). There was a significant main difference in students' perceptions of the utility of the workshop (Welch's $(3,46.76)=3.52, p=.022)$ and the perceived relevance of the workshop (Welch's $(3,35.92)=3.48, p=.026)$. However post hoc analyses indicated that there were no further inter-group differences. In addition, there were no other significant main differences in students' perceptions of the workshop in terms of clarity, understandability, organisation, or level of interest.

\section{[INSERT TABLE 1]}

Findings indicated that students in their first and third years consistently reported higher endorsement of the workshop contents in comparison to students in their second year or those registered on the shortened programme. For example almost ninety percent of students in their $3^{\text {rd }}($ $n=34,87 \%)$ and $1^{\text {st }}$ year $(n=34,90 \%)$ of their course rated the clarity of the workshop as 9 or above out of ten, just under two thirds of students in their $2^{\text {nd }}$ year $(n=26,65 \%)$ and on the shortened course $(n=9,64 \%)$ provided a similar score for clarity. A similar pattern was identified for other elements (Table 2).

\section{[INSERT TABLE 2]}

\section{Preferred timing within midwifery programmes}

The majority of students reported a preference to begin learning about workplace-related trauma in the first year of their programme (Table 3); $68 \%(n=26)$ of students in the first year, $40 \%(n=16)$ of those in their second year, $64 \%(n=9)$ of those on the shortened programme, and $59 \%(n=23)$ of those in their third year endorsed this option. In addition, approximately a fifth to one third of students (21-35\%) in each group (first year $n=10,26 \%$; second year $n=14,35 \%$; shortened programme $n=3,21 \%$ and third year $n=9,23 \%$ ) indicated that they would prefer to receive information on work-related trauma and PTSD at a combination of time points throughout their course (Table 3).

\section{[INSERT TABLE 3]}


Written feedback obtained from students in relation to this item on the survey emphasised a preference to begin learning about the POPPY material in the first year of their course to raise awareness and facilitate preparation for entering into clinical placements;

- "PTSD can occur at any time - I think it is important to have an understanding of it early on" (Y1, HEl1)

- "Awareness needs to be raised from the beginning. Traumatic events also happen in 1st year and it may be even harder to process with not much experience" (Y2, HEI2)

- "Students need to be aware from the beginning so they're aware of what to look out for and when to seek help" (Y3 HEI2)

- "Intense course - good to have support" (shortened programme, HEI1)

For those expressing a preference to learn about the POPPY material at a combination of time points, this most often involved beginning to learn about trauma in their first year but continuing to revisit the material throughout their course;

- "Good to recap yearly. Remind ourselves how to deal with situations" (Y2, HEl1)

- "First year would be helpful as an example, the first birth I ever witnessed on my first placement was traumatic and I did not have the skills to deal with it, however first year learning is very intense and the skills workshop at this point would probably need to be repeated again throughout the course to be maintained and used in context as experience is gained" (Y3, HEI2)

\section{Method of delivery}

The largest proportion of students from each year group indicated that they preferred to receive information on trauma and PTSD as part of a standalone session. This included nearly three quarters of first year students ( $n=27,73 \%)$, nearly two thirds of second year students $(n=25,63 \%)$, fifty percent of students on the shortened course and just under sixty percent of third year students $(n=22,58 \%)$; see Table 4 for further details. In addition to this, the majority of first year $(n=34$, $90 \%)$, second year $(n=37,93 \%)$, shortened course $(n=12,86 \%)$ and third year students $(n=14$, 93\%) reported that the workshop was just about the right length in time. Written feedback from students emphasised the perceived value of receiving information about trauma and selfmanagement of early responses in one session; 
- "It has been useful gaining all the info in $1 x$ session and I now feel equipped to recognise and rectify PTSD and symptoms" (Y2, HEl1)

- "As it was designated entirely to the topic it will be easy to remember the content" (Y1 HEI2)

Some students felt that integrating the workshop material into a series of sessions within one module would enable a greater depth of understanding to be obtained. Others also recognised that aspects of the PreR-POPPY workshop held relevance to other modules already part of their course;

- "Would provide opportunity to gain more info and ask questions that arise after the info is given" (Y3, HEl1)

- "I think this subject can be inserted into many of the modules we do - e.g., communication, clinical skills, holistic" (Y1 HEI2)

\section{[INSERT TABLE 4]}

\section{Recommendation to other students}

Overall, 98.5\% of students who received the PreR-POPPY workshop would recommend the session to other pre-registration midwifery students (Table 5). Written feedback illustrated the positive responses from those who attended:

- "So interesting! So useful! On a personal and professional level. Lots of useful tools, helped to ensure an open mind!" (Y1 HEl1)

- "Makes us more aware of PTSD and what can lead up to developing the disorder, can also prepare us for traumatic events and how to cope in traumatic situations" (Y1 HEI2)

- "Very helpful coping mechanisms and helps understand why and how these thoughts are developed and can be normal" (Y3 HEI2)

- "I think it was very interesting and helpful and I think it will help me daily in my practice and also to understand other people that may suffer of this condition working in my environment at work" (shortened programme, HEl1)

\section{[INSERT TABLE 5]}

\section{Personal understanding and skills about trauma}

Mean scores across each of these four domains were high (mean range 8.23-9.06, maximum 10), indicating that students felt relatively confident in the understanding and skills they had learnt during the workshop (Table 6). There were no significant differences identified in students' confidence in 
their knowledge of trauma $(F(3,127)=1.21, p=.308)$, knowledge of responses to trauma ( $F(3$, $127)=1.91, p=.132$, confidence in recognising early symptoms of trauma $(F(3,127)=1.26$, $\mathrm{p}=.291$, or confidence in managing early responses to trauma $(F(3,126)=.997, p=.396)$ between year groups.

\section{[INSERT TABLE 6]}

When scores were grouped based on a response of 9 or above for each learning outcome, evidence of variability between groups was identified. Although between 64 and $93.3 \%$ of students felt highly confident in their knowledge of trauma and responses to trauma, the proportion of those feeling as confident in their ability to recognise and manage early trauma symptoms varied from 30.8 to $71.2 \%$. A similar pattern was identified, with the smallest proportion of students reporting high levels of confidence in understanding and skills identified in the $2^{\text {nd }}$ year group (for confidence in understanding trauma), and students on the shortened programme for skills relating to understanding responses to trauma, recognition and management of early trauma responses (please see Table 7).

\section{[INSERT TABLE 7]}

\section{Ways to improve}

1. Content and stylistic improvements $(n=81)$

Suggested methods to improve the content of the PreR-POPPY workshop included greater depth on PTSD and management of early responses, providing additional time to explore strategies, and the use of more midwifery-based examples of experiencing trauma and PTSD. Students also endorsed the use of visual aids (e.g., videos) to facilitate engagement throughout the workshop, or the use of role-play as a discussion activity.

- "Perhaps making it a longer workshops- especially relating to strategies to cope" (Y3 HEl1)

- "Maybe include an anonymous example of a real- life midwife's experience, how they felt and what they did to overcome it" (Y1 HEl1)

- "More time for exercises - would help to understand how to utilise them (i.e., observe, label, pass by)." (Y2 HEI2)

- "Videos- people talking about their experiences of PTSD and how it affected them and how they overcame it" (Y3 HEI1)

2. Further resources and support $(n=13)$ 
Some students suggested that the inclusion of additional resources (e.g., a handout, booklet, elearn module, summary sheet) that could be used after the workshop would help to consolidate learning. Other students suggested that information about where to access further support within their University included in their pack would be beneficial. There were also comments about the inclusion of one-to-one sessions after the workshop to enable students to discuss any difficulties they may be having with the workshop facilitator. One student suggested the introduction of a peer support system within the course.

- "E-learn module to go with it. Certificate of participation for our portfolios!" (Y3 HE/2)

- "Access to information on Blackboard" (shortened HEI1)

- "Possibility of appointing a student/ students to act as peer supporters within the cohort/ across all 3 years" (Y3 HEI2)

- "Have the uni provide details of where to contact them if someone was concerned (included in the pack)" (Y2 HEI1)

\section{Feedback from midwifery educators}

Midwifery educators from both host HEls provided unanimous endorsement and recognition that there is a place for the PreR-POPPY workshop in pre-registration midwifery training. The workshop was considered timely given the recent changes to midwifery supervision, reductions in resources and increases in stress and burnout and that POPPY is relevant not only for students at the beginning of their midwifery career but also for those with prior experience in a caring profession. Endorsement was also received from all present at the meeting that the work should be drawn to the attention of the NMC team developing the new education standards for midwifery.

\section{DISCUSSION}

The adapted POPPY training module is perceived as very acceptable and useful for provision as part of pre-registration midwifery programmes. Almost all of the student midwives who received the PreR-POPPY training would recommend the workshop to other pre-registration midwifery students, which highlights that students perceived the opportunity to learn about trauma and trauma responses as valuable and of use for all students undergoing midwifery training. Regardless of year group differences, the overall scores and written comments provided by student midwives were indicative of very high levels of satisfaction with the contents of the workshop, and of high endorsement for its utility and relevance for their midwifery training. Feedback from midwifery educators further emphasised the endorsement received for the future provision of PreR-POPPY in pre-registration midwifery training. 
Providing the PreR-POPPY training during year 1 of a training programme, but following this up at a later time point in the course, would meet the needs of over eighty percent of students. Feeling isolated, unable to discuss difficult events encountered on placement and a perceived absence of a supportive culture were described by students in a recent qualitative investigation (Coldridge \& Davies, 2017). As a result, students described 'shutting down' to the emotional demands of their role. The provision of the PreR-POPPY workshop early in training would raise awareness about the potential to experience trauma potentially prior to any such experience, and equip students with the skills for self-managing early stress responses should they arise. It could also help to foster a supportive culture whereby impacts of traumatic events are acknowledged, to help counteract the described perception that talking about adverse impacts could be seen as "weak and inefficient" (Coldridge \& Davies, 2017, p. 4). Davies and Coldridge (2015) cited a requirement to discuss potentially distressing aspects of the midwifery role early in midwifery programmes, and findings from the present study emphasise the acceptability of this from the perspective of students.

It is plausible to suggest that the trend for a smaller proportion of students on the shortened course to report high levels of satisfaction with the PreR-POPPY workshop could in part be attributed to the differing levels of prior experience with clinical scenarios. Students registered on the shortened BSc course will have already undertaken training to become a registered general (adult) nurse, whereas those registered on the 3 year programme will have a different level of experience in acute clinical settings. Students in their second year of the direct entry course also reported similar levels of satisfaction as those on the shortened course. Second year of the direct entry midwifery course involves placements where childbirth is not straightforward and more complex. Written comments provided by students indicated that lower scores were often attributed to the view that the workshop would be more beneficial if provided earlier in their course. Therefore rather being indicative of dissatisfaction with the utility of the workshop for practise, lower scores here may in part be due to the increasing exposure to care of women with complicated maternities and an awareness of the educational and preventative value of the workshop if provided earlier.

\section{Implications}

Pre-registration midwifery programmes have, since September 2015, been required to include modular content related to women's perinatal mental health. However midwives' mental health also requires consideration as a means of providing high-quality, empathic care. PreR-POPPY training should be integrated into pre-registration programmes and ideally take place at an early point with follow up sessions scheduled throughout the course. This is in alignment with current recognition of the requirement to develop methods to support students to prepare for the emotional demands of midwifery practice (Beaumont et al., 2016; Power \& Mullan, 2017), and reflects the feedback obtained from the midwifery educators regarding the relevance of PreR-POPPY for the current and future midwifery workforce. The National Maternity Review documents the Five Year Forward View 
for maternity services in England to provide women with greater continuity of carer, facilitating empathic and woman-centred quality care (NHS England, 2016). Developing a relationship with a woman has been associated with an increased risk of PTSD in qualified midwives (Leinweber \& Rowe, 2010; Sheen et al., 2014) and has been identified as an aspect increasing difficulty for student midwives following an adverse event (Coldridge \& Davies, 2017). It is essential therefore that students are equipped with the necessary information and skills to support their own psychological wellbeing at the earliest opportunity. This type of educational preparation approach as a preventive strategy with tailored adaptations may ultimately have a wider utility across other health related disciplines with trauma exposure.

\section{Limitations}

The PreR-POPPY workshop was evaluated as part of a feasibility evaluation of the wider POPPY programme. Whilst findings highlight a high level of endorsement from students regarding the acceptability and utility of the workshop, further research is required to identify the effectiveness of the training material particularly on whether it reduces training attrition. In addition HEls may need to consider establishing systems that incorporate the other stepped support elements of the full POPPY package, namely peer support and access to trauma-focussed psychological therapy. Follow up of these cohorts has potential to yield important information about how the PreR-POPPY knowledge and skills were utilised and its impact on attrition.

\section{CONCLUSIONS}

The PreR-POPPY workshop adapted from the POPPY programme, which is the first PTSD prevention strategy for midwives and clearly fulfils an important gap in provision for pre-registration students. This workshop adaptation was very well received, and almost without exception recommended for other midwifery students and fulfilled its short term learning objectives. It now needs rollout and impact evaluation in terms of student attrition.

\section{REFERENCES}

American Psychological Association., 2013. Diagnostic and Statistical Manual of Mental Disorders (V). American Psychiatric Association, Washington DC. 
Barry, M., Quinn, C., Bradshaw, C., Noonan, M., Brett, M., Atkinson, S., New, C., 2017. Exploring perinatal death with midwifery students' using a collaborative art project. Nurse education today $48,1-6$.

Cohen, R., Leykin, D., Golan-Hadari, D., Lahad, M., 2017. Exposure to traumatic events at work, posttraumatic symptoms and professional quality of life among midwives. Midwifery 50, 1-8.

Braun, V., Clarke, V., 2006. Using thematic analysis in psychology. Qualitative research in psychology 3 (2), 77-101.

Coldridge, L., Davies, S., 2017. "Am I too emotional for this job?" An exploration of student midwives' experiences of coping with traumatic events in the labour ward. Midwifery 45, 1-6.

Davies, S., Coldridge, L., 2015. 'No Man 's Land': An exploration of the traumatic experiences of student midwives in practice. Midwifery 31 (9), 858-864.

Beaumont, E., Durkin, M., Martin, C. J. H., Carson, J., 2016. Compassion for others, selfcompassion, quality of life and mental well-being measures and their association with compassion fatigue and burnout in student midwives: A quantitative survey. Midwifery 34 , 239-244.

Elmir, R., Pangas, J., Dahlen, H., Schmied, V., 2017. A meta-ethnographic synthesis of midwives' and nurses' experiences of adverse labour and birth events. Journal of Clinical Nursing 26 (23-24), 4184- 4200.

Leinweber, J., Creedy, D. K., Rowe, H., Gamble, J., 2017a. Responses to birth trauma and prevalence of posttraumatic stress among Australian midwives. Women and Birth 30 (1), 40 45.

Leinweber, J., Creedy, D. K., Rowe, H., Gamble, J., 2017b. A socioecological model of posttraumatic stress among Australian midwives. Midwifery 45, 7-13.

Leinweber, J., Rowe, H. J., 2010. The costs of 'being with the woman': secondary traumatic stress in midwifery. Midwifery 26 (1), 76-87.

NHS England., 2016. Better births: Improving outcomes of maternity services in England - A five year forward view for maternity care. Retrieved from:

https://www.england.nhs.uk/publication/better-births-improving-outcomes-of-maternityservices-inengland-a-five-year-forward-view-for-maternity-care/

National Institute for Clinical Excellence. (2005). Post-traumatic stress disorder: management [CG26].Manchester, UK. Retrieved from: https://www.nice.org.uk/guidance/cg26

Royal College of Midwives., 2017a. Agency, Bank and Overtime Spending in UK Maternity Units in 2016. Retrieved from:

https://www.rcm.org.uk/sites/default/files/Agency\%20Bank\%20and\%200vertime\%20Spe nding\%202017\%20A4\%2016pp 2\%20\%282\%29\%20FINAL.pdf 
Royal College of Midwives., 2017b. The gathering storm: England's midwifery workforce challenges.

Retrieved from:

https://www.rcm.org.uk/sites/default/files/The\%20gathering\%20storm\%20-

\%20Englands\%20midwifery\%20workforce\%20challenges\%20A5\%2020pp_3.pdf

Sheen K., Slade P. Spiby H., 2014. An integrative review of the impact of indirect trauma exposure in health professionals and potential issues of salience for midwives. Journal of Advanced Nursing 70 (4), 729-743.

Sheen, K., Spiby, H., Slade, P., 2015. Exposure to traumatic perinatal experiences and posttraumatic stress symptoms in midwives: prevalence and association with burnout. International Journal of Nursing Studies 52 (2), 578- 587.

Sheen, K., Spiby, H., Slade, P., 2016a. What are the characteristics of perinatal events perceived to be traumatic by midwives? MIDWIFERY 40, 55-61.

Sheen, K., Spiby, H. Slade, P., 2016b. The nature and perceived impact of traumatic perinatal event experiences in midwives: A qualitative investigation. International Journal of Nursing Studies 53, 61-72.

Power, A., Mullan, J., 2017. Vicarious birth trauma and post-traumatic stress disorder: Preparing and protecting student midwives. British Journal of Midwifery 25 (12), 799-802.

Wahlberg, Å., Andreen Sachs, M., Johannesson, K., Hallberg, G., Jonsson, M., Skoog Svanberg, A., Högberg, U., 2016. Post-traumatic stress symptoms in Swedish obstetricians and midwives after severe obstetric events: a cross-sectional retrospective survey. BJOG: An International Journal of Obstetrics \& Gynaecology 124 (8), 1264- 1271. 
Table 1. Student feedback (out of a maximum of 10) on the content of the PreR-POPPY workshop

\begin{tabular}{|c|c|c|c|c|c|}
\hline & Year 1/3 & Year 2/3 & Year 3/3 & $\begin{array}{l}18 \text { month } \\
\text { programme }\end{array}$ & Overall \\
\hline Clarity $(\mathrm{N})$ & 38 & 40 & 39 & 14 & 131 \\
\hline Mean (SD) & $9.53(.83)$ & $8.87(1.49)$ & $9.44(.79)$ & $9.14(1.10)$ & $9.26(1.11)$ \\
\hline Median (range) & $10(7-10)$ & $10(5-10)$ & $10(7-10)$ & $10(7-10)$ & $10(5-10)$ \\
\hline $\begin{array}{l}\text { Understandabilit } \\
\text { y }(N)\end{array}$ & 38 & 40 & 39 & 14 & 131 \\
\hline Mean (SD) & $9.34(.85)$ & $9.02(1.21)$ & $9.38(1.02)$ & $8.50(1.35)$ & $9.17(1.10)$ \\
\hline Median (range) & $10(7-10)$ & $9.5(6-10)$ & $10(6-10)$ & $8.5(7-10)$ & $10(6-10)$ \\
\hline Organisation (N) & 38 & 40 & 39 & 14 & 131 \\
\hline Mean (SD) & $9.68(.66)$ & $9.35(1.00)$ & $9.72(.51)$ & $9.43(.65)$ & $9.56(.76)$ \\
\hline Median (range) & $10(7-10)$ & $10(6-10)$ & $10(8-10)$ & $9.5(8-10)$ & $10(6-10)$ \\
\hline Interesting (N) & 38 & 40 & 38 & 14 & 130 \\
\hline Mean (SD) & $9.58(.83)$ & $9.02(1.39)$ & $9.34(.85)$ & $8.93(1.45)$ & $9.27^{i}(1.08)$ \\
\hline Median (range) & $10(7-10)$ & $10(5-10)$ & $10(8-10)$ & $9(6-10)$ & $10(5-10)$ \\
\hline Utility $(\mathrm{N})$ & 38 & 40 & 39 & 14 & 131 \\
\hline Mean (SD) & $9.53(.80)$ & $8.98(1.42)$ & $9.49(1.10)$ & $8.43(1.45)$ & $9.23(1.22)$ \\
\hline Median (range) & $10(7-10)$ & $10(5-10)$ & $10(6-10)$ & $8(6-10)$ & $10(5-10)$ \\
\hline Relevance $(\mathrm{N})$ & 31 & 28 & 31 & 11 & 101 \\
\hline Mean (SD) & $9.48(1.24)$ & $9.11(1.34)$ & $9.69(1.75)$ & $8.55(1.21)$ & $9.34(1.18)$ \\
\hline Median (range) & $10(4-10)$ & $10(5-10)$ & $10(7-10)$ & $8(6-10)$ & $10(4-10)$ \\
\hline
\end{tabular}

Table 2. Proportion of students scoring $\geq 9$ for each aspect of workshop contents by year of programme

\begin{tabular}{|c|c|c|c|c|c|}
\hline & Year 1/3 & Year 2/3 & Year 3/3 & $\begin{array}{l}18 \text { month } \\
\text { programme }\end{array}$ & Overall \\
\hline Clarity N (\%) & $\begin{array}{l}34 / 38 \\
(89.5)\end{array}$ & $\begin{array}{l}26 / 40 \\
(65.0)\end{array}$ & $\begin{array}{l}34 / 39 \\
(87.2)\end{array}$ & $9 / 14(64.2)$ & $103 / 131(78.6)$ \\
\hline $\begin{array}{l}\text { Understandability N } \\
(\%)\end{array}$ & $\begin{array}{l}33 / 38 \\
(86.8)\end{array}$ & $\begin{array}{l}27 / 40 \\
(67.5)\end{array}$ & $\begin{array}{l}33 / 39 \\
(84.6)\end{array}$ & $7 / 14(50.0)$ & $100 / 131(76.3)$ \\
\hline Organisation N (\%) & $\begin{array}{l}36 / 38 \\
(94.7)\end{array}$ & $\begin{array}{l}32 / 40 \\
(80.0)\end{array}$ & $\begin{array}{l}38 / 39 \\
(97.4)\end{array}$ & $13 / 14(92.9)$ & $119 / 131(90.8)$ \\
\hline Interesting N (\%) & $\begin{array}{l}34 / 38 \\
(89.5)\end{array}$ & $\begin{array}{l}29 / 40 \\
(72.5)\end{array}$ & $\begin{array}{l}29 / 38 \\
(76.3)\end{array}$ & $11 / 14(88.6)$ & $103 / 130(79.2)$ \\
\hline Utility N (\%) & $\begin{array}{l}35 / 38 \\
(92.1)\end{array}$ & $\begin{array}{l}26 / 40 \\
(65.0)\end{array}$ & $\begin{array}{l}33 / 39 \\
(84.6)\end{array}$ & $6 / 14(42.8)$ & $100 / 131(76.3)$ \\
\hline Relevance N (\%) & $\begin{array}{l}28 / 31 \\
(90.3)\end{array}$ & $\begin{array}{l}20 / 28 \\
(71.4)\end{array}$ & $\begin{array}{l}28 / 31 \\
(90.3)\end{array}$ & $5 / 11(45.5)$ & $/ 101(80.2)$ \\
\hline
\end{tabular}

Table 3. Preferred timing of workshop

\begin{tabular}{rrrrrr}
\hline & Year 1/3 & Year 2/3 & Year 3/3 & $\begin{array}{r}\text { 18 month } \\
\text { programme }\end{array}$ & Overall \\
\hline $\mathrm{N}$ & 38 & 40 & 39 & 14 & 131 \\
\hline Never & & $0(0)$ & $0(0)$ & $0(0)$ & $0(0)$ \\
Year 1 & $26(68.4)$ & $16(40.0)$ & $23(59.0)$ & $9(64.3)$ & $74(56.4)$ \\
Year 2 & $2(5.3)$ & $8(20.0)$ & $6(15.4)$ & $2(14.3)$ & $18(13.7)$ \\
Year 3 & $0(0)$ & $1(2.5)$ & $1(2.6)$ & - & $2(1.5)$ \\
A combination & $10(26.3)$ & $14(35.0)$ & $9(23.1)$ & $3(21.4)$ & $36(27.5)$ \\
Post registration & $0(0)$ & $1(2.5)$ & $0(0)$ & $0(0)$ & $1(.8)$ \\
\hline
\end{tabular}


Table 4. Preferred method of delivery

\begin{tabular}{rrrrrr} 
& Year 1/3 & Year 2/3 & Year 3/3 & $\begin{array}{r}18 \text { month } \\
\text { programme }\end{array}$ & Overall \\
\hline $\mathrm{N}$ & 37 & 37 & 38 & 14 & 126 \\
Standalone session & $27(73.0)$ & $25(62.5)$ & $22(57.9)$ & $7(50.0)$ & $81(64.3)$ \\
Series in different & $5(13.5)$ & $6(15.0)$ & $8(21.1)$ & $3(21.4)$ & $22(17.5)$ \\
modules & & & & & \\
Series in one module & $3(8.1)$ & $4(10.0)$ & $7(18.4)$ & $4(28.6)$ & $18(14.3)$ \\
In another way & $2(5.4)$ & $2(5.0)$ & $1(2.6)$ & $0(0)$ & $5(4.0)$ \\
\hline
\end{tabular}

Table 5. Recommendation to other midwifery students

\begin{tabular}{rrrrrr}
\hline & Year 1/3 & Year 2/3 & Year 3/3 & $\begin{array}{c}18 \text { month } \\
\text { programme }\end{array}$ & \multicolumn{1}{c}{ Overall } \\
\hline Yes & $38(100)$ & $38(95.0)$ & $39(100)$ & $14(100)$ & $129(98.5)$ \\
No & & $1(2.5)$ & & & $1(.75)$ \\
Unsure & & $1(2.5)$ & & & $1(.75)$ \\
\hline
\end{tabular}

Table 6. Learning outcomes (out of a maximum of 10) for trauma and early responses to trauma

\begin{tabular}{|c|c|c|c|c|c|c|}
\hline & & Year 1/3 & $\begin{array}{l}\text { Year } \\
2 / 3\end{array}$ & Year 3/3 & $\begin{array}{c}18 \text { month } \\
\text { programme }\end{array}$ & Overall \\
\hline \multirow{3}{*}{$\begin{array}{r}\text { Understand nature of } \\
\text { traumatic event }\end{array}$} & $\mathrm{N}$ & 38 & 40 & 39 & 14 & 131 \\
\hline & $M(S D)$ & $9.00(.93)$ & $\begin{array}{r}8.839 \\
(.96)\end{array}$ & $9.21(.89)$ & $8.86(.95)$ & $\begin{array}{l}8.99 \\
(.93)\end{array}$ \\
\hline & $\begin{array}{l}\text { Median } \\
\text { (range) }\end{array}$ & $9(7-10)$ & $9(7-10)$ & $9(7-10)$ & $9(7-10)$ & $9(7-10)$ \\
\hline $\begin{array}{r}\text { Understand types of } \\
\text { early stress }\end{array}$ & $M(S D)$ & $\begin{array}{r}8.95 \\
(1.11)\end{array}$ & $\begin{array}{l}9.18 \\
(.87)\end{array}$ & $9.23(.90)$ & $8.57(1.09)$ & $\begin{array}{l}9.06 \\
(.99)\end{array}$ \\
\hline responses & $\begin{array}{l}\text { Median } \\
\text { (range) }\end{array}$ & $9(7-10)$ & $9(7-10)$ & $9(7-10)$ & $9(7-10)$ & $9(7-10)$ \\
\hline $\begin{array}{l}\text { Confidence } \\
\text { recognising early }\end{array}$ & $M(S D)$ & $\begin{array}{r}9.00 \\
(1.07)\end{array}$ & $\begin{array}{r}8.53 \\
(1.57)\end{array}$ & $\begin{array}{r}8.92 \\
(1.04)\end{array}$ & $8.57(1.16)$ & $\begin{array}{r}8.79 \\
(1.25)\end{array}$ \\
\hline responses & $\begin{array}{l}\text { Median } \\
\text { (range) }\end{array}$ & $9(7-10)$ & $9(3-10)$ & $9(6-10)$ & $9(6-10)$ & $9(3-10)$ \\
\hline $\begin{array}{r}\text { Confidence in } \\
\text { managing early }\end{array}$ & $M(S D)$ & $\begin{array}{r}8.51^{\mathrm{a}} \\
(1.04)\end{array}$ & $\begin{array}{r}8.20 \\
(1.59)\end{array}$ & $\begin{array}{r}8.13 \\
(1.26)\end{array}$ & $7.86(1.46)$ & $\begin{array}{r}8.23^{b} \\
(1.34)\end{array}$ \\
\hline responses & $\begin{array}{l}\text { Median } \\
\text { (range) }\end{array}$ & $9^{b}(6-10)$ & $9(1-10)$ & $8(5-10)$ & $8(5-10)$ & $8(1-10)$ \\
\hline
\end{tabular}

Note. ${ }^{a} n=37,{ }^{b} n=131$

Table 7. Proportion of students scoring 9+ for each learning outcome by year group

\begin{tabular}{lrrrrr} 
& Year 1/3 & Year & Year & 18 month & Overall \\
& & $2 / 3$ & $3 / 3$ & programme & \\
\hline Confidence in understanding trauma & $26 / 38$ & $26 / 40$ & $29 / 39$ & $11 / 14$ & $92 / 131$ \\
$\mathrm{~N}(\%)$ & $(68.4)$ & $(65.0)$ & $(74.4)$ & $(78.5)$ & $(70.2)$ \\
\hline Confidence in understanding & $26 / 38$ & $32 / 40$ & $31 / 39$ & $8 / 14$ & $97 / 131$ \\
responses to trauma N (\%) & $(68.4)$ & $(80.0)$ & $(70.8)$ & $(57.1)$ & $(74.0)$ \\
\hline Ability to recognise trauma & $27 / 38$ & $24 / 40$ & $26 / 39$ & $8 / 14$ & $85 / 131$ \\
responses N (\%) & $(71.1)$ & $(60.0)$ & $(66.7)$ & $(57.1)$ & $(64.9)$ \\
\hline
\end{tabular}




$(51.4) \quad(42.5) \quad(30.8)$

(35.7) (40.5)

